American Journal of Economics and Business Administration 2 (3): 307-316, 2010

ISSN 1945-5488

(C) 2010 Science Publications

\title{
Leptospirosis in the Tropics: When Prevention Doesn't Easily Sell as a Ton of Cure
}

\author{
Roger Lee Mendoza \\ Cherry Hill, New Jersey 08003, USA
}

\begin{abstract}
Problem statement: Human leptospirosis -- the most widespread zoonotic disease -- thrives in tropical and subtropical climates. It is seldom addressed ex ante or prior to an outbreak or expected outbreak by governments of high-risk countries. Whether common, post-exposure treatment with antimicrobial drugs is more cost-efficient than reducing animal reservoir populations was the overarching question that guided this study. A related question in this study was how to establish comparability of pertinent price or cost estimates. Approach: Annualized price samples of government-approved, antimicrobial therapies and proposed rat and other rodent chemical agents (rodenticides) were gathered from three leptospirosis-endemic countries: Brazil, the Philippines and Sri Lanka. Certain price data were adjusted for present value based on a linear cost accounting function. Two-tailed hypothesis-testing $(\alpha=0.05)$ was performed to determine any statistically significant differences in pricing antimicrobial therapies and rodenticides in each country under investigation. Results: Shared socio-demographic characteristics of infected populations appear to support the need for ex ante containment of rat/rodent reservoir populations in tropical and subtropical countries. In each surveyed country, we found $\mathrm{t}_{\text {crit }}>\mathrm{t}_{\mathrm{obs}}>-\mathrm{t}_{\text {crit }}$. Therefore, the null hypothesis, $\mu_{\text {antimicrobial }}=\mu_{\text {rodenticides }}=$ $\mu_{\text {antimicrobial }}-\mu_{\text {rodenticides }}=0$, could not be rejected in favor of the alternative, $\mu_{\text {antimicrobial }} \neq \mu_{\text {rodenticides }}=$ $\mu_{\text {antimicrobial }}-\mu_{\text {rodenticides }} \neq 0$. Conclusion: Applications of Price Estimation (PE) methods in financial economics, such as present value, help optimize health decisions concerning zoonotic diseases. Leptospira transmission in Brazil, the Philippines and Sri Lanka illuminate the need for broad and cohesive policies that take into account zoocentric measures. These may be critical in high-risk, tropical and subtropical countries that periodically experience flooding, standing water and increased rainfall.
\end{abstract}

Key words: Antibiotic prophylaxis, antimicrobial drugs, demonstration effects, ex ante, exposure, leptospirosis, present value, price estimation, rodenticides, zoocentric, zoonosis

\section{INTRODUCTION}

Leptospirosis as a zoonosis: Leptospirosis is the most geographically widespread zoonosis (i.e., an infectious disease that is transmitted to humans by animals). It is caused by pathogenic spirochetes of the genus Leptospira and acquired through contact with animal reservoirs and/or an environment contaminated by their urine and feces. These include ingestion of contaminated food and water or by broken skin and mucous membrane contact with contaminated water and soil (Levett, 2001; Vijayachari et al., 2008). Clinical presentations of leptopspirosis among humans range from asymptomatic infection to potentially fatal zoonosis. The majority of human infections are mild, systemic illnesses that bring headache, chills, fever, conjunctival suffusion and muscle pain (Levett, 2001; Shieh et al., 2005). However, human mortality from its severe forms -Weil's syndrome and severe pulmonary hemorrhage syndrome -- is relatively high with rates of over $10 \%$ and $50 \%$, respectively, even when optimal treatment is provided (McBride et al., 2005).

Leptospirosis is an emerging public health concern worldwide (Vijayachari et al., 2008). Lestospira exposure occurs much more frequently in tropical and subtropical regions because of the longer survival of this bacteria as well as frequent human exposure to contaminated environments. Within these regions, the Philippines, Borneo Island (Brunei, Indonesia and Malaysia), the Indochinese peninsula, the Okinawa prefecture Sri Lanka, Brazil, Cuba and Guatemala report the highest incidence rates per annum. These places appear to have common environmental denominators that facilitate bacterial spread. One is standing water as a result of flooding during the monsoon season in East, South and Southeast Asia, post-hurricane flooding and increased waterfall in the Amazon rainforest. Another is rat and other rodent infestation, which is further encouraged by tropical and subtropical climates. Scientific studies have 
consistently indicated that rats are the most significant carriers and transmitters of leptospirosis globally, although other domestic and wild animals are potential reservoirs of the bacteria (Sarkar et al., 2002; GreenMcKenzie and Shoff, 2010; Villanueva et al., 2010). Several Leptospira serovars and serogroups that circulate among rats have already been identified (McBride et al., 2007). Many cities in underdeveloped tropical countries are leptospirosis-endemic, as the growth of slum settlements has produced conditions favorable to rapid rat-borne transmission of the disease. These include open sewers, refuse and inadequate floodwater drainage. In addition to the environmental attributes of slums, low socio-economic classification has been found to independently contribute to the risk of human infection (Reis et al., 2008).

Current barriers to addressing leptospirosis include inadequate diagnostic tests and control measures (McBride et al., 2005). No human vaccine has yet been developed specifically for the disease. Mild leptospirosis is often treated with antibiotics, such as doxycycline, ampicillin or amoxicillin. For severe leptospirosis, the primary therapy is penicillin G; alternative regimens are ampicillin, amoxicillin or erythromycin (GreenMcKenzie and Shoff, 2010). Hence, human leptospirosis is typically addressed ex post facto or after Leptospira exposure (or as a result of an anticipated outbreak), through prescription of antimicrobial drugs, particularly antibiotics (Kobayashi, 2005).

Objectives of the study: Because leptopspirosis is seldom treated ex ante or before an outbreak occurs, this study was conducted to examine the validity of the view held by health officials in several developing countries that controlling the sources of Leptospira is necessarily costlier than antimicrobial therapies. Part of this study is to determine how to establish comparability of pertinent price or cost estimates.

Delimitation of the study: The cost effectiveness of empirical and prophylactic therapy has been analyzed elsewhere (Galloway et al., 2009). On the other hand, a cost-benefit or cost-effectiveness analysis of ex ante reduction in rat and other rodent reservoir populations is beyond the scope of this inquiry. Rather, this study offers a comparative financial analysis of pre-exposure and post-exposure health measures using rodenticides (poisonous chemicals for rodent extermination) as pricing models for zoocentric (carrier/transmitterfocused) health measures. In doing so, the study offers a model for testing the efficacy of health policy assumptions and explores the benefits of interdisciplinary collaboration between disciplines like economics and epidemiology to generate more prevention models of zoonosis in human societies.

\section{MATERIALS AND METHODS}

Selection criteria: Three leptospirosis-endemic countries, Brazil, the Philippines and Sri Lanka, were analyzed in terms of pricing and related cost information for: (1) commonly prescribed antimicrobial drugs, (antibiotic prophylaxis and other medicines that prevent the onset of leptospirosis) and (2) mostly slowacting rodenticides in the form of anticoagulants, hypercalcemia and other products (e.g., bacterial products) that can counter "bait shyness" (bait rejection by rodents due to observed immediate fatal effect on other rodents). Electronic devices (e.g., lethal electrified barriers) as well as manual methods, like entrapment, that are sometimes employed in farming areas to control animal leptospirosis, have been omitted from our price samples. They are highly unlikely to be approved by governments for use in high-risk human populations due to concerns about their safety, effectiveness and financial cost. Pricing information was gathered from the three countries' health, environment and/or agriculture agencies. Other sources were cost estimates from pest control/extermination firms, some of which had been submitted to these agencies.

The three countries met the following selection criteria: (1) broad geographic representation of the tropics; (2) documented rat/rodent infestation problems; (3) recent major outbreaks of human leptospirosis (in contrast to animal leptospirosis); (4) government preference for antimicrobial/prophylactic treatment over zoocentric measures due to the latter's financial cost or budgetary implications and (5) availability and accessibility of comparative financial data. A brief review of related literature, devoted to the sociodemographic characteristics of infected populations, precedes the presentation of empirical results for each country.

Adjusted present value: Certain price estimates had to be adjusted for their present value, as the concept is understood in financial economics (Smart and Megginson, 2008). To predict present (and future) costs in financial economics, a cost function is specified and statistically determined through tests that are expected to yield high r-squared and t-values (Khan, 2000; Smart and Megginson, 2008). These statistical tests provide tools for price or cost estimation or prediction, particularly if available information is somewhat dated.

In modifying the standard price or cost formula to account for the present value of rodenticide or pest control estimates, we sought to determine annual pricing for relatively comparable populations and 
geographic settings using country-specific interest rates and data over a period of 3-5 prior years. The 3-5 year time frame corresponded to available annual price data for antimicrobial and prophylactic treatments that were previously administered by their governments. Periodicity of flooding and increased rainfall in the surveyed countries explains the annual basis for price estimation. Determination of a Price Estimate (PE) was therefore based on the total amount that a series of future payments or budgetary outlays is presently worth to significantly reduce animal reservoir populations per annum (particularly rats and other rodents in tropical and subtropical countries). The estimation procedure, in turn, assumed a series of constant payments and constant interest rates given our 3-5 year time frame.

Prior to adjusting for present value, the PE formula for flexible budgeting was preceded by a standard cost function in linear form:

$y=a+b x$

Where:

$\mathrm{y}=$ The semi-variable (or mixed) costs to be broken up

$\mathrm{x}=$ Any given measure of activity, such as volume and labor-hours

$\mathrm{a}=$ The fixed cost component

$\mathrm{b}=$ The variable rate per unit of $\mathrm{x}$

To summarily illustrate, the cost-volume formula for a rodent exterminator's overhead is $y=\$ 200.00+$ $\$ 10.00 \mathrm{x}$, where $\mathrm{y}=$ estimated exterminator's overhead and $\mathrm{x}=$ direct labor-hours. The exterminator's overhead is estimated to be $\$ 200.00$ fixed, plus an additional $\$ 10.00$ per hour of direct labor cost.

To determine any percentage unit change for $\mathrm{y}$, a multiplier in the form of our adjusted present value (apv) equation was used:

$$
\operatorname{apv}=\frac{\left.[(\mathrm{pmt}) *(1+\text { rate })(\text { type })]^{*}\left[(1+\text { rate })^{\mathrm{n}} \text { per }-1 / \text { rate }\right]-\mathrm{fv}\right]}{(1+\text { rate })^{\mathrm{n}} \text { per }}
$$

Where:

$\mathrm{fv} \quad=$ Future value

Rate $=$ Rate per period

Nper $=$ Number of periods

Pmt = Payment amount

Type $=1$ if payments are made at the beginning of each period

Type $=0$ if payments are made at the end of each period

Therefore, (1) and (2) yield the PE:
$\mathrm{PE}=(\mathrm{y})(\mathrm{apv})$

Hypothesis testing of independent means: Having generated the PE to establish currency and comparability for randomly sampled prices, a twotailed test of independent group means was performed to determine relative equality in mean pricing for antimicrobial therapies (group 1) and rodenticides (group 2) in each of the three countries under study.

The degrees of freedom (df) in an unpaired twogroup t-test when the group (sample or population) size $<30$ is derived from:

$\mathrm{df}=\mathrm{n}_{1}+\mathrm{n}_{2}-2$

Where:

$\mathrm{n}=$ Size (number of price estimates) of the group

$1=$ group 1 (control group)

$2=$ group 2 (experimental group)

The Standard Error of the mean (SE-) was estimated based on the sample estimate of the population standard deviation (or sample standard deviation) divided by the square root of the group size, $\mathrm{n}$, in view of the statistical independence of the price or cost estimates in each of the two groups:

$\mathrm{SE}_{\overline{\mathrm{x}}}=\frac{\mathrm{S}}{\sqrt{\mathrm{n}}}$

Where:

$\mathrm{s}=$ Group standard deviation (i.e., the sample-based estimate of the standard deviation of the population)

$\mathrm{n}=$ Size (number of price estimates) of the group

This estimate may be compared with the formula for the true standard deviation of the mean:

$$
\mathrm{SD}_{\overline{\mathrm{x}}}=\frac{\sigma}{\sqrt{\mathrm{n}}}
$$

Where:

$\sigma=$ The standard deviation of the population

The computational formula for the standard error of the difference between means, $\operatorname{SE}\left(\overline{\mathrm{x}}_{1}-\overline{\mathrm{x}}_{2}\right)$, which was designed to also handle unequal group sizes, offers a statistical index of the probability that a difference between the statistical means of the two groups (or samples) under study is greater than 0 . The standard 
error of the difference between the means is expressed as follows:

$$
\operatorname{SE}\left(\overline{\mathrm{x}}_{1}-\overline{\mathrm{x}}_{2}\right)=\sqrt{\left(\frac{\mathrm{SS}_{1}+\mathrm{SS}_{2}}{\mathrm{n}_{1}+\mathrm{n}_{2}-2}\right)\left(\frac{1}{\mathrm{n}_{1}}+\frac{1}{\mathrm{n}_{2}}\right)}
$$

Where:

$\mathrm{n}_{1}=$ Number of price/cost estimates in group 1

$\mathrm{n}_{2}=$ Number of price/cost estimates in group 2

$\mathrm{SS}_{1}=$ Sum of squares for group 1 for determining its variance

$\mathrm{SS}_{2}=$ Sum of squares for group 2 for determining its variance

Provided that:

$$
\begin{aligned}
& \mathrm{SS}_{1}=\sum \mathrm{X}_{1}^{2}-\frac{\left(\sum \mathrm{X}_{1}\right)^{2}}{\mathrm{n}_{1}} \\
& \mathrm{SS}_{2}=\sum \mathrm{X}_{2}^{2}-\frac{\left(\sum \mathrm{X}_{2}\right)^{2}}{\mathrm{n}_{2}}
\end{aligned}
$$

When (6) is divided by the standard error, the result is a t-statistic for two independent group means $(\mathrm{n}<30)$ :

$$
\mathrm{t}=\frac{\mathrm{X} 1-\mathrm{X} 2}{\sqrt{\left(\frac{\mathrm{SS}_{1}+\mathrm{SS}_{2}}{\mathrm{n}_{1}+\mathrm{n}_{2}-2}\right)\left(\frac{1}{\mathrm{n}_{1}}+\frac{1}{\mathrm{n}_{2}}\right)}}
$$

Where:

$\mathrm{X}_{1}=$ Mean for group 1

$\mathrm{X}_{2}=$ Mean for group 2

Having established the basic t-test parameters (47), the null hypothesis was formulated as follows:

$\mathrm{H}_{0}: \mu_{\text {antimicrobial }}=\mu_{\text {rodenticides }}=\mu_{\text {antimicrobial }}-\mu_{\text {rodenticides }}=0$

In contrast, the non-directional alternative hypothesis was formulated as follows:

$\mathrm{H}_{\mathrm{a}}: \mu_{\text {antimicrobial }} \neq \mu_{\text {rodenticides }}=\mu_{\text {antimicrobial }}-\mu_{\text {rodenticides }} \neq 0$

Where:

$\mu_{\text {antimicrobial }}=$ Mean annual price of group 1 (government-sponsored/prescribed antimicrobial therapies: ex post facto health measure) $\mu_{\text {rodenticides }}=$ Mean annual price of group 2 (proposed rodenticides/rodent control: ex ante health measure)

Lastly, we have set the decision criteria to reject $\mathrm{H}_{0}$ if and only if:

$\mathrm{t}_{\text {crit }}<\mathrm{t}_{\text {obs }}<-\mathrm{t}_{\text {crit }} ;$ or, summarily, $\mathrm{p}<\alpha=0.05$

Where:

$\mathrm{t}_{\mathrm{obs}}=$ Computed or observed t-statistic

$\mathrm{t}_{\text {crit }}=$ Corresponding critical value for $\mathrm{t}$ given $\mathrm{df}$ and $\alpha$

$\mathrm{p}=$ Probability value for obtaining $\mathrm{t}_{\mathrm{obs}}$

$\alpha=$ Level of significance

\section{RESULTS}

Brazil (South America): Brazil is the world's fifth largest (and South America's largest) country in terms of both geographical area and population. It comprises a wide range of weather conditions across a vast area and varied topography, but most of the country is tropical.

Although it still contains approximately $60 \%$ of the Amazon rainforest (sustaining the world's greatest biodiversity), Brazil has undergone dramatic demographic transformation due to the rapid growth of urban areas in the last 60 years. Outbreaks of leptospirosis occur most frequently in urban slum communities (favelas) during seasonal periods of heavy rainfall each year (Ko et al., 1999). These favelas are the loci of the vast majority of leptospirosis cases because of poor sanitation that particularly favor ratborne transmission of Leptospira (De Faria et al., 2008; Silva et al., 2009). One study found that the number of rats sighted by local residents was correlated with their risk of acquiring Leptospira antibodies. It suggested that rat sightings are a reliable indicator of infection risk where inhabitants are accustomed to the presence of rats. Additionally, the study found that raising chicken in the household significantly increased the risk of infection, since rats are easily attracted to chicken feed and waste (Reis et al., 2008).

Like most of its South and Central American neighbors, the vast majority of leptospirosis cases in Brazil are reported from January to April when increased rainfall is experienced. The national incidence rate is 1.9 per 100,000 (Hartskeerl, 2005). Approximately 10,000 cases are reported each year from all major Brazilian cities. A 29-year study of São Paulo, Brazil's most populated state, indicated that 
most infected patients were males ( $87 \%)$, aged between 20+ and 39 years (Romero et al., 2003). Neither federal nor state governments have yet taken concrete zoocentric measures to reduce the most prevalent carrier-transmitter of leptospirosis in this country (especially the so-called brown rat that thrives in urban slum conditions).

Table 1 summarizes unpaired t-test results for randomly selected, government-initiated prophylactic antibiotic treatments $(\mathrm{n}=8)$ and rodenticide PEs $(\mathrm{n}=$ 4). Each group constituted approximately $80 \%$ of available pricing models gathered primarily from the federal Epidemiology Surveillance Department. Because the computed t-statistic $=1.4204$ was less than 2.3060 and greater than -2.3060 , we failed to reject $\mathrm{H}_{0}$ in order to accept $\mathrm{H}_{\mathrm{a}}$. Summarily, the two-tailed $\mathrm{p}=$ $0.1933>0.05$. There is therefore evidence that the prices and PEs for the two anti-leptospirosis strategies were not significantly different.

Philippines (Southeast Asia): Outbreaks of leptospirosis in the Philippines have been associated with heavy rainfall and flooding during the monsoon season, rapid urbanization and growth of urban slums, deforestation and poor infrastructures. In 2007, the mean age of infected patients was 32 years old. Males accounted for $87 \%$ and outdoor workers for $70 \%$ of the infected population. Most patients resided in the low-lying or below-sea level (flood-prone) areas of Metro Manila and the adjacent Calabarzon region (Yanagihara et al., 2007).

Two successive tropical storms in 2009, codenamed Ondoy and Pepeng, caused massive flooding in Metro Manila and the Calabarzon provinces of Rizal and Laguna, from which a major leptopspirosis outbreak ensued. The Department of Health reported 2,158 positive cases in 2009, including 167 deaths, which represented a three-fold increase from the 769 cases reported nationwide in 2008.

Table 1: Brazil, two-tailed t-test (BRL = Brazilian Reais)

\begin{tabular}{lll}
\hline Parameter & Antimicrobial therapies & Rodenticides \\
\hline$\overline{\mathrm{x}}=$ & $2,078,139.33 \mathrm{BRL}$ & $12,698,144.25 \mathrm{BRL}$ \\
$\mathrm{s}=$ & $838,734.54 \mathrm{BRL}$ & $18,884,314.52 \mathrm{BRL}$ \\
$\mathrm{SE} \overline{\mathrm{x}}=$ & $342,411.94 \mathrm{BRL}$ & $9,442,157.26 \mathrm{BRL}$ \\
$\mathrm{n}=$ & 6 & 4 \\
$\mu_{1}-\mu_{2}=$ & $-10,620,004.92 \mathrm{BRL}$ & \\
$95 \% \mathrm{CI}\left(\mu_{1}-\mu_{2}\right)=$ & $-27,861,871.06$ to $6,621,861.23 \mathrm{BRL}$ \\
$\mathrm{t}_{\mathrm{obs}}=$ & 1.4204 \\
Two-tailed $\mathrm{t}_{\text {crit }}=$ & \pm 2.3060 \\
$\mathrm{df}=$ & 8 \\
SE $\mathrm{x} 1-\mathrm{x} 2=$ & $7,476,941.579 \mathrm{BRL}$ \\
Two-tailed $\mathrm{p}=$ & 0.1933 \\
Decision $=$ & $\mathrm{H}_{0}:$ not rejected; $\mathrm{p}>\alpha=0.05$ (two-tailed)
\end{tabular}

In the aftermath of Ondoy and Pepeng, varying anti-rodent campaigns were waged in the Philippines. These ranged from Bayer Philippines' Rat Attack information dissemination programs and distribution of free Racumin products to various municipal ordinances that offered cash payments for every rat caught dead or alive by local residents (Laude, 2009; Philippine Star, 2010). Rat infestation has long been a serious problem, in a country where millions of rats are born annually (Philippine Star, 2010; Villanueva et al., 2010). One study has discovered at least four Leptospira serovars and serogroups circulating among domestic rats in the Philippines. It underscored the role of these domestic rats as natural carrier and shedder of pathogenic Leptospires in the epidemiology of Philippine urban leptospirosis (Yanagihara et al., 2007). A 1999 report further noted that:

\begin{abstract}
Although no official statistics exist, rodent populations are believed to be rising. [At] the height of the dry conditions during the El Niño weather system, farmers in one province estimated that they were slaughtering around 800 rats a night in their rice fields. An effective rodent control programme is the best means of preventing leptospirosis, health officials have suggested. [However], the Department of Health does not have the budget for this. For the time being, the department has issued advice to all government health clinics warning people not to wade or swim in the floodwaters (Easton, 1999)
\end{abstract}

Despite calls from several health groups and experts, the Philippine government has yet to adopt concrete measures designed to curb the growing rat and other rodent populations in Metro Manila, the Calabarzon and other highly infested areas. In November 2009, the Department of Health issued its Interim Guidelines on the Prevention of Leptospirosis through the Use of Prophylaxis in Areas Affected by Floods to guide hospitals serving infected patients. That same year, the antibiotic prophylactic program run for 10 weeks to distribute 4 million antibiotics and other medicines in typhoon-affected areas requiring a total budgetary outlay of 40 million Philippine pesos from the Department of Health (ABS-CBN News.com, 2009).

Price samples for antibiotic prophylaxis were obtained from Department of Health and World Health Organization reports as well as private exterminators in the Philippines. Rodenticide price samples included sustained baiting with multiple-dose anticoagulant rodenticides, pulsed baiting with brodifacoum, metal phospides and other poisonous chemicals. 
Table 2: Philippines, two-tailed t-test (PHP = Philippine Pesos)

\begin{tabular}{lll}
\hline Parameter & Antimicrobial therapies & Rodenticides \\
\hline$\overline{\mathrm{x}}=$ & $28,519,857.14$ PHP & $43,917,800.00$ PHP \\
$\mathrm{s}=$ & $16,593,353.39$ PHP & $22,243,430.02$ PHP \\
$\mathrm{SE} \overline{\mathrm{x}}=$ & $6,271,698.07$ PHP & $9,947,564.32$ PHP \\
$\mathrm{n}=$ & 7 & 5 \\
$\mu_{1}-\mu_{2}=$ & $-15,397,942.86$ PHP \\
$95 \% \mathrm{CI}\left(\mu_{1}-\mu_{2}\right)=$ & $-40,258,972.65$ to $9,463,086.94$ PHP \\
$\mathrm{t}_{\text {obs }}=$ & 1.3800 \\
Two-tailed $\mathrm{t}_{\text {crit }}=$ & \pm 2.281 \\
$\mathrm{df}=$ & 10 \\
SE & $11,157,752.428$ PHP \\
Two-tailed $\mathrm{p}=$ & 0.1976 \\
Decision $=$ & $\mathrm{H}_{0}:$ not rejected; $\mathrm{p}>\alpha=0.05$ (two-tailed) \\
\hline
\end{tabular}

Table 3: Sri Lanka, two-tailed t-test (LKR = Sri Lankan Rupees)

\begin{tabular}{lll}
\hline Parameter & Antimicrobial therapies & Rodenticides \\
\hline$\overline{\mathrm{x}}=$ & $114,974,254.57 \mathrm{LKR}$ & $116,993,916.50 \mathrm{LKR}$ \\
$\mathrm{s}=$ & $11,353,654.86 \mathrm{LKR}$ & $17,091,969.64 \mathrm{LKR}$ \\
$\mathrm{SE} \overline{\mathrm{x}}=$ & $4,291,278.17 \mathrm{LKR}$ & $4,934,026.64 \mathrm{LKR}$ \\
$\mathrm{n}=$ & 7 & 12 \\
$\mu_{1}-\mu_{2}=$ & $-2,019,661.93 \mathrm{LKR}$ & \\
$95 \% \mathrm{CI}\left(\mu_{1}-\mu_{2}\right)=$ & $-17,386,206.71$ to $13,346,882.85 \mathrm{LKR}$ \\
$\mathrm{t}_{\text {obs }}=$ & 0.2773 \\
Two-tailed $\mathrm{t}_{\text {crit }}=$ & \pm 2.1098 \\
$\mathrm{df}=$ & 17 \\
$\mathrm{SE}$ & \\
Two-tailed $\mathrm{p}=$ & $7,283,356.982 \mathrm{LKR}$ \\
Decision $=$ & 0.7849 \\
\hline
\end{tabular}

Two-tailed t-test results for Metro Manila and the Calabarzon provinces (the regions for which financial data were sufficient) are summarized in Table 2. The difference in price means for antimicrobial drugs approved and distributed by the Department of Health and proposed rodent control chemical agents does not appear to be statistically significant, given that $2.2281>\mathrm{t}_{\mathrm{obs}}>-2.2281$. Specifically, there is insufficient evidence that the estimated annual financial costs of employing rodenticides for comparable areas and populations in Metro Manila and the Calabarzon significantly vary from prophylactic antibiotics. However, antiobiotic prophylaxis remains the most common, post-exposure treatment that the national government prescribes to residents in flood-prone areas during the monsoon season.

Sri Lanka (South Asia): With one of the highest leptospirosis incidence worldwide (35.7 per 100,000 as of 2008), Sri Lanka has experienced major outbreaks of the disease at the rate of once every 4 to 5 years. The Asian tsunami in 2004 resulted in one such outbreak. Unusually heavy monsoon flooding in 2008 led to global record-breaking numbers of Sri Lankans who were suspected for infection $(7,099)$ and tested positive for the disease $(4,500$, of which 1,150 were fatalities $)$.
The mean age of infected Sri Lankans in 2008 was 40 years. About $81 \%$ of them were males. The majority of all infected patients $(61 \%)$ had been exposed to paddy fields (for farming), while $24 \%$ were exposed to muddy or marsh lands (Sri Lanka Ministry of Healthcare and Nutrition, 2008).

Rat infestation has accounted in large part for the high incidence rate of Lestospira infection, which in Sri Lanka is better known as "rat fever" (McIndoe, 2009). As one government report underscored:
High humidity and heavy rain fall intensify outbreaks because of widespread contamination by rodent urine in flood water (Rodents are displaced from their burrows and drains by the flood water). Annually there are two peaks in the disease incidence, at the time of the monsoons, a smaller one during March May and a larger one during October- December (Sri Lanka Ministry of Healthcare and Nutrition, 2009)

In the past, the Sri Lankan federal government did not directly address the problem of rat infestation due to the expected lower cost and logistical efficiency of antiobiotic prophylaxis. Following the devastating floods of the previous year, the Ministry of Health and Nutrition in 2009 agreed in principle to implement the use of the Cuban-manufactured Bio Rat (bacterial product) to control leptospirosis. Official approval by the Registrar of Pesticides and the Ministry of Agriculture are still needed, as Bio Rat could potentially lead to adverse effects on the eco-system (Agampodi et al., 2009).

The independent t-test results for Sri Lanka are shown on Table 3 . The areas represented by our price data include Colombo, Gampaha in the Western Province, Matale in the Central Province, Kurunegala in the North Western Province and Kegalle in the Sabaragamuwa Province. These are among the worst affected areas, with Matale and Kegalle accounting for the highest incidence rate in 2008. Higher group $\mathrm{n}$ for rodenticides, including bacterial products, owes mainly to the federal government's recent support for and adoption of, some zoocentric strategies to counter the rapidly rising rat population nationwide. Such health policy appears to have stimulated the growth of a rodent extermination market since 2009.

Despite the larger $\mathrm{n}$ and $\overline{\mathrm{x}}$ for rodenticides (i.e., compared to Brazil's and the Philippines'), we find no sufficient statistical basis for the lower price per capita of antibiotics and other antimicrobial agents in Sri Lanka, ceteris paribus. By conventional criteria, the 
means difference cannot be considered as statistically significant at 2.1098> $\mathrm{t}_{\mathrm{obs}}>-2.1098$. With the computed $\mathrm{p}=0.7849>0.05, \mathrm{H}_{0}$ likewise failed to be rejected in the Sri Lankan case.

\section{DISCUSSION}

Statistically insufficient price differences: In all the three countries that we surveyed, hypothesis testing yielded relatively consistent results, after price data were controlled for three key factors: target location, population and timeline. Had per country $p<0.05$, there would have been the probability of little overlap between the two distributions. Because $p>0.05$ per country and $t$ did not fit into the critical region, we could expect a fair amount of overlap between the two groups. The empirical results of this study thus lead to the conclusion that mean price differences could easily have arisen through mere coincidence. There was insufficient statistical basis to reject $\mathrm{H}_{0}$ in favor of $\mathrm{H}_{\mathrm{a}}$ in the Brazilian, Philippine and Sri Lankan cases.

One insight we may gain from our empirical findings is the need for objective or empirical assessment on the part of decision-makers concerning the financial costs of health policy alternatives. Critical ex ante health measures, such as reducing animal reservoir populations, may initially appear to be costlier in absolute terms. However, when price or cost estimates are adjusted to establish currency and comparability and subsequently tested for statistical significance, the empirical results could challenge the prevailing view about the financial cost implications of post-exposure or remedial measures.

Interdisciplinary approach: Another insight derives from the importance of interdisciplinary collaboration between epidemiology and economics, particularly the need and possibilities for an exchange of their respective analytical models. Testing methods, such as squared scores and cost accounting methods, such as apv, exemplify the benefits of interdisciplinary research in examining the validity of key assumptions behind the choice of health policies and strategies. The t-statistic was employed in our hypothesis testing to compare the significance of price differences between the means of antimicrobial agents and slow-acting rodenticides, given that the two groups were independent of one another, although each had a relatively small $\mathrm{n}$. The squaring procedure (i.e., the sum of squares) is a more recent statistical method designed to estimate statistical variance of (smaller) independent groups. It determined how spread the prices in each of the two groups were. Each sum of squares is the sum of the squared scores in each group less the sum of the scores quantity squared divided by the sample size, $n$. The t-value is the difference between the two group means divided by their sum of squares, while taking into account their corresponding df. The independent $t$-value therefore relies on the summation $\mathrm{X}$ and summation $\mathrm{X}$ squared for each group, in addition to the group means and group sizes. Apv, on the other hand, was intended to adjust the standard PE methods in financial economics (Cook and Holzmann, 1976) to achieve comparability of target sites and populations within predetermined time frames for implementing anti-leptospirosis measures. Interdisciplinary research offers opportunities for the methodologies of other disciplines to transcend the confines of traditional cost-efficiency calculations and further enhance cost validation procedures in epidemiology.

The limitations that we encountered in establishing price comparability based on apv reflect the varying nature of the problems and concerns of each surveyed country, including disease occurrence, rural (or farming) and urban infrastructures and population density and distribution. These factors affect each country's health objectives, needs and priorities when an outbreak of leptospirosis occurs or is anticipated. They also highlight the risks of extrapolating from ad hoc country cases to regional and global levels or trends.

At the same time, even assuming one were to find an aberration in the geographic representation of the three selected countries, the findings of this study nonetheless challenge the widely held assumption among their respective decision-makers -- as reported in their media -- that zoocentric measures, like rodent vector control, are financially costlier than commonly adopted prophylactic/chemoprophylactic treatments following an outbreak. The findings of this study will hopefully encourage decision-makers to carefully and thoughtfully investigate the efficacy of policy alternatives that may well be "worth a ton of cure". Future regional and country studies that may employ, improve or revise the testing and price estimation methods we have used here could replicate and verify our findings and help optimize decisions about leptospirosis prevention and control in high-risk human populations. Therein lies the challenge of interdisciplinary research in epidemiology.

Zoocentric containment: The consistency of test results in Brazil, the Philippines and Sri Lanka appeared to be matched by the consistency of the sociodemographic characteristics of their affected populations based on our review of relevant literature. 
We found the vast majority of leptospirosis patients to be low-income males, aged 40 years and below, who often reside in urban (slum) and rat-infested rural areas. Exposure to Leptospira is typically and directly attributed to their dwelling conditions, livelihood (e.g., paddy farming, fishing, poultry-raising and even scavenging) and mobility patterns during an environmental disaster (e.g., wading in floodwater to get to work or save lives and property). There are variations in the incidence of infection among the three countries, particularly on the basis of geographic setting (e.g., higher rates in urban slums as opposed to rural paddies and during the monsoon months in South and Southeast Asia in contrast to periods of increased rainfall in the Amazon countries of Latin America). For these reasons, we attempted to establish geographic and population comparability by adopting and adjusting the present value method in financial economics.

Two key points lend support to the importance of systematically controlling the transmission sources of leptospirosis in the tropics.

On the one hand, our literature review found that the use of appropriate rodenticides and destruction of rodent breeding grounds can successfully diminish the risk of leptospirosis infection (Faine, 1998; Mohan Rao, 2006; World Health Organization, 2006). Rats were unquestionably the major reservoir of Leptospira organisms in Brazil, the Philippines and Sri Lanka. Rat and many other rodent breeding periods commence with the southwest monsoon, suggesting that appropriate pest control measures in the pre-monsoon period could bring better vector control, usually through the use of slow acting rodenticides (Mohan Rao, 2006).

On the other hand, the limitations and side effects of using antimicrobial agents have been studied and identified. An extensive study of the scientific evidence for and against the use of antibiotics in Leptospira infection indicated "conflicting results" and concluded that the "[u] se of antibiotics may or may not prevent leptospirosis" depending on the affected individuals (Brett-Major and Lipnick, 2009). Doxycycline, for example, has been found to significantly increase the odds for nausea and vomiting with unclear benefit in reducing Leptospira seroconversion or the clinical consequences of infection (Brett-Major and Lipnick, 2009). The benefit of antibiotics after the fifth day of the disease is also controversial, although most clinicians treat with antibiotics regardless of the date of onset of the illness (Brett-Major and Lipnick, 2009; World Health Organization, 2009). Vaccination may be an option but it could easily provoke immune responses to the serovars included in the vaccine (World Health
Organization, 2009), which perhaps account for its slow development for human cases of Leptospira infection. Finally, diagnostic tests for Leptospira infection remain inadequate to date. A wide range of symptoms is often mistaken for a simple viral infection commonly treated with antibiotics.

Hence, one other insight that may be derived from this study is the need for a zoonosis to be equally addressed from a zoocentric policy perspective. Such a policy draws attention to the infection source and the route of transmission between the infection source and the human host, with the objective of reducing rodent reservoir populations using appropriate or approved methods. It counterbalances the preeminence of postexposure treatments, such as antibiotic prophylaxis. Rodent vector control also tends to focus on the carriers' environmental dispersal and behavior, as part of a broader and coordinated public health strategy that may include improved drainage system in flooded areas, occupational hygiene and epidemiological surveillance of trouble areas, among others. This is particularly critical "[i]n much of the developing world, where laboratory capabilities for confirmation of acute leptospiral infection are lacking, [and] leptospirosis as an acute disease is rarely considered in clinical differential diagnoses (Laras et al., 2002). The experiences of leptospirosis-endemic countries like Brazil, the Philippines and Sri Lanka illuminate the need for and importance of, zoocentric public health strategies.

Demonstration effects of public health policy: Zoocentric containment of Leptospira transmission, if officially and systematically pursued, could be expected to exert demonstration effects on households, firms and markets. These catalytic behavioral consequences of any change or shift in existing public health policies or measures arise from the rearrangement of incentives and disincentives in the production, distribution and regulation of goods and services (Mendoza, 2010a; Mendoza, 2010b).

In India (Sri Lanka's northern neighbor), the timing of rat vector control was shown to be a vital consideration in the prevention of Leptospira infection (Mohan Rao, 2006). Sri Lanka, albeit lacking any prior empirical cost study, had opted in 2009 to consider rodent vector control largely as a result of India's successful experience. In turn, this policy shift has spurred the growth of a rodent extermination market. Promotion of Racumin anticoagulants and similar products in the Philippines, on the other hand, has taken a less aggressive marketing path (i.e., through corporate-sponsored educational programs and distribution of free product samples). The Philippine 
government has yet to enact systematic rodent vector control policies. However, the urgent need to do so following the destruction brought by typhoons Ondoy and Pepeng in 2009 (e.g., high-level policy discussions and clamor of health groups and experts) has sent sufficient trade signals to the rodent extermination industry to anticipate and prepare for such a change.

The demonstration effects of any form of zoocentric containment underscore the vital role of governments in determining and evaluating appropriate control methods and devices. Because reducing animal reservoir populations require a longer time frame and carries environmental spillover effects compared to antibiotic therapies, further studies of cost-effectiveness are needed to address issues of safety, suitability and efficiency. Interdisciplinary collaboration between decision-makers and the health and scientific communities is crucial in this regard. Public information dissemination of appropriate control methods is equally important (e.g., household-based applications of rodenticides in Brazilian favelas may differ from Sri Lanka's rice paddy areas). In the words of one economist, "[w]hat is most important is to strike a proper balance between free trade and environmental protection" because both "are crucial for the well-being of human society" (Jaiswal, 2010). It is also in this manner that markets can perform a catalytic role in the control of zoonotic diseases.

\section{ACKNOWLEDGMENT}

The author wishes to acknowledge with thanks the helpful comments and suggestions made by this journal's anonymous peer reviewers and his faculty colleagues who reviewed various drafts of this study in the summer of 2010 .

\section{REFERENCES}

ABS-CBN News.com, 2009. RP's leptospirosis outbreak one of the world's biggest. ABS-CBN News. $\quad$ http://www.abscbnnews.com/nation/10/22/09/rps-leptospirosisoutbreak-one-worlds-biggest

Agampodi, S., S.J. Peacock and V. Thevanesam, 2009. The potential emergence of leptospirosis in Sri Lanka. Lancet Infect. Dis., 9: 524-526. DOI: 10.1016/S1473-3099(09)70211-7

Brett-Major, D.M. and R.J. Lipnick, 2009. Antibiotic prophylaxis for leptospirosis. Cochrane Database Syst. Rev., 8: CD007342-CD007342. PMID: 19588424

Cook, J.S. and O.J. Holzmann, 1976. Current cost and present value in income theory. Account. Rev., 51: 778-787. http://www.jstor.org/stable/246125
De Faria, M.T., M.S. Calderwood, D.A. Athanazio, A.J. McBride and R.A. Hartskeerl et al., 2008. Carriage of Leptospira interrogans among domestic rats from an urban setting highly endemic for leptospirosis in Brazil. Acta Trop., 108: 1-5. PMID: 18721789

Easton, A., 1999. Leptospirosis in Philippine floods. BMJ, 319: 212-212. PMID: 10417074

Faine, S., 1998. Leptospirosis. In: Bacterial Infections of Humans: Epidemiology and Control, Evans, A.S. and P.S. Brachman (Eds.). Springer, New York, pp: 395-420.

Galloway, R.L., P.N. Levett, J.W. Tumeh and C.R. Flowers, 2009. Assessing cost effectiveness of empirical and prophylactic therapy for managing leptospirosis outbreaks. Epidemiol. Infect., 137: 1323-1332. DOI: $10.1017 / \mathrm{S} 0950268808001751$

Green-McKenzie, J. and W.H. Shoff, 2010. Leptospirosis in humans. eMedicine. http://emedicine.medscape.com/article/788751overview

Hartskeerl, R.A., 2005. International leptospirosis society: Objectives and achievements. Rev. Cubana Med. Trop., 57: 7-10. http://bvs.sld.cu/revistas/mtr/vol57_1_05/mtr01105.pdf

Jaiswal, S.K., 2010. Development or the environment. Am. J. Econ. Bus. Admin., 1: 257-262. http://www.scipub.org/fulltext/ajeba/ajeba13257262.pdf

Khan, M.Y., 2000. Theory and Problems in Financial Management. 2nd Edn., Tata McGraw Hill, Boston, pp: 441.

Ko, A.I., M. Galvão Reis, C.M. Ribeiro Dourado, W.D. Johnson Jr. and L.W. Riley, 1999. Urban epidemic of severe leptospirosis in Brazil. Lancet, 354: 820-825. DOI: $10.1016 / \mathrm{S} 0140-$ 6736(99)80012-9

Kobayashi, Y., 2005. Human leptopspirosis: Management and prognosis. J. Postgrad Med., 51: 201-204. PMID: 16333193

Laras, K., B.V. Cao, K. Bounlu, T.K. Nguyen and J.G. Olson et al., 2002. The importance of leptospirosis in Southeast Asia. Am. J. Trop. Med. Hyg., 67: 278-286. PMID: 12408667

Laude, P., 2009. Valenzuela councilor offers residents: P5 per rat caught. The Philippine Star. http://www.philstar.com/Article.aspx?articleid=525555

Levett, P.N., 2001. Leptospirosis. Clin. Microbiol. Rev., 14: 296-326. PMID: 11292640

McBride, A.J.A., D.A. Athanazio, M.G. Reis and A.I. Ko, 2005. Leptospirosis. Curr. Opin. Infect. Dis., 18: 376-386. http://journals.lww.com/co- 
infectiousdiseases/Abstract/2005/10000/Leptospiro sis.3.aspx

McBride, A.J.A., B.L. Santos, A. Queiroz, A.C. Santos and R.A. Hartskeerl et al., 2007. Evaluation of four whole-cell leptospira-based serological tests for diagnosis of urban leptospirosis. Clin. Vaccine Immunol., $\quad 14$ : 1245-1248. DOI: 10.1128/CVI.00217-07

McIndoe, A., 2009. Manila, after the floods, battles rat fever. Time.

http://www.time.com/time/world/article/0,8599,19 32199,00.html

Mendoza, R.L., 2010a. The economics of autism in Egypt. Am. J. Econ. Bus. Admin., 2: 12-19. http://www.scipub.org/fulltext/ajeba/ajeba211219.pdf

Mendoza, R.L., 2010b. Aspirin in cardiovascular and cerebrovascular events: Does market failure matter? Am. J. Econ. Bus. Admin., 2: 120-128. http://www.scipub.org/fulltext/ajeba/ajeba21120128.pdf

Mohan Rao, A.M.K., 2006. Preventive measures for leptospirosis: Rodent control. Indian J. Med. Microbiol., 24: 325-328. DOI: 10.4103/02550857.29410

Philippine Star, 2010. Racumin's ratAttack goes to Mandaluyong. Philippine Star. http://www.philstar.com/Article.aspx? articleId $=58$ 9149\&publicationSubCategoryId=75

Reis, R.B., G.S. Ribeiro, R.D.M. Felzemburgh, F.S. Santana and S. Mohr et al., 2008. Impact of environment and social gradient on Leptospira infection in urban slums. PLoS Negl. Trop. Dis., 2: e228-e228. DOI: 10.1371/journal.pntd.0000228

Romero, E.C., C.C.M. Bernardo and P.H. Yasuda, 2003. Human leptospirosis: A twenty-nine year serological study in Sao Paulo, Brazil. Rev. Inst. Med. Trop. S. Paulo, 45: 245-248. http://www.scielo.br/pdf/rimtsp/v45n5/a02v45n5.pdf

Sarkar, U., S.F. Nascimento, R. Barbosa, R. Martins and H. Nuevo et al., 2002. Population-based casecontrol investigation of risk factors for leptospirosis during an urban epidemic. Am. J. Trop Med. Hyg., 66: 605-610. http://www.ajtmh.org/cgi/reprint/66/5/605

Shieh, W., C. Edwards, P., Levett and S. Zaki, 2005. Leptospirosis. In: Tropical Infectious Diseases: Principles, Pathogens and Practice, Guerrant, R.L., D.H. Walker and P.F. Weller (Eds.). Churchill Livingstone, Philadelphia, pp: 511-518.
Silva, E.F., G.M. Cerqueira, N. Seyffert, F.K. Seixas and D.D. Hartwig et al., 2009. Leptospira noguchii and human and animal leptospirosis, Southern Brazil. Emerg. Infect. Dis., 15: 621-623. DOI: 10.3201/eid1504.071669

Smart, S. and W.L. Megginson, 2008. Introduction to Corporate Finance. 1st Edn., Thomson Learning, Stamford, pp: 736.

Sri Lanka Ministry of Healthcare and Nutrition, 2008. An interim analysis of Leptospirosis outbreak in Sri Lanka-2008. Sri Jayawardenapura Kotte. http://www.epid.gov.lk/pdf/Leptospirosis/An\%20I nterim\%20Analysis\%20of\%20Leptospirosis\%200 utbreak\%20in\%20Sri\%20Lanka\%202008.pdf

Sri Lanka Ministry of Healthcare and Nutrition, 2009. Study of leptospirosis outbreak in Sri Lanka in Kurunegala District-2008. Kurunagala. http://lirneasia.net/wpcontent/uploads/2009/06/study-of-leptospirosisoutbreak-in-sri-lanka.pdf

Vijayachari, P., A.P. Sugunan and A.N. Shriram, 2008. Leptospirosis: An emerging global public health problem. J. Biosci., 33: 557-569. PMID: 19208981

Villanueva, S.Y.A.M., H. Ezoe, R.A. Baterna, Y. Yanagihara and M. Muto et al., 2010. Serologic and molecular studies of Leptospira and leptospirosis among rats in the Philippines. Am. J. Trop. Med. Hyg., 82: 889-898. DOI: 10.4269/ajtmh.2010.09-0711

World Health Organization, 2006. Guidelines for prevention and control of leptospirosis. National Institute of Communicable Diseases. http://www.whoindia.org/LinkFiles/Communicable _Diseases_Guidelines_for_Prevention_and_Contro 1_Leptospirosis.pdf

World Health Organization, 2009. Leptospirosis fact sheet. Regional Office for South-East Asia. http://www.searo.who.int/LinkFiles/CDS_leptospir osis-Fact_Sheet.pdf

Yanagihara, Y., S.Y.A.M. Villanueva, S.I. Yoshida, Y. Okamoto and T. Masuzawa, 2007. Current status of leptospirosis in Japan and Philippines. Comparat. Immunol. Microbiol. Infect. Dis., 30: 399-413. DOI: 10.1016/j.cimid.2007.05.003 